\title{
Study The Effect of Process Parameters of CNC Milling Surface Generation Using Al-alloy 7024
}

\author{
Nareen Hafidh Obaeed ${ }^{1}$, Mostafa Adel Abdullah ${ }^{1}$, Momena Muath $^{1}$, Maryam Adnan ${ }^{1}$, Hind Amir ${ }^{1}$ \\ ${ }^{1}$ Department of Production Engineering and Metallurgy - University of Technology - Baghdad, Iraq. \\ *corresponding author: email address: nareen_5005@yahoo.com
}

\begin{abstract}
A wonderful unique research developments in modeling surface roughness and optimization of the predominant parameters to get a surface finish of desired level since only suitable selection of cutting parameters can get a better surface finish, so the objective of this work is to study the milling process parameters which include tool diameter, feed rate, spindle speed, and depth of cut resulting in optimal values of the surface roughness during machining AL-alloy 7024. The machining operation implemented on XK7124 3-axis CNC milling machine. The effects of the selected parameters on the chosen characteristics have been accomplished using Taguchi's parameter design approach. The parameters considered are - depth of cut with two levels $(0.2,0.5$ $\mathrm{mm})$, tool diameter with two levels $(6,8 \mathrm{~mm})$, spindle speed with two levels $(1000,2500 \mathrm{rpm})$, and finally feed rate with two levels $(200,500 \mathrm{~mm} / \mathrm{min})$. Analysis of the results showed that the optimal settings for low values of surface roughness are large tool diameter $(8 \mathrm{~mm})$, high spindle speed (2500 r.p.m), low feed rate $(200 \mathrm{~mm} / \mathrm{min})$ and high depth of cut $(0.5 \mathrm{~mm})$. Response Table for mean of surface roughness showed that tool diameter has the most effected factors (rank one) followed by feed rate (rank two) then depth of cut which is the third effected factors and finally spindle speed with the less effected factors of surface roughness (rank four).
\end{abstract}

Keywords: surface roughness; milling operation; Bezier surface; Taguchi technique; CNC milling machine.

Paper History: (Received:17-04-2018; Accepted :27-062018)

\section{INTRODUCTION}

Geometric modeling is the process in which a geometric model is established to represent the size and shape of a component. The mathematical representation of curves, surfaces, and solids deals with modeling that needed during the definition of combination physical or engineering subjects [1]. The modeling of geometry, using analytic and differential geometry, methods of matrix, tensors, topology, set theory, and an arsenal of numerical computation methods to grasp the potentially complex description of an object, requires the power of a computer [2].

The important measure of the technological quality of a product is the surface roughness; this factor greatly influences the manufacturing cost [3]. Surface roughness of the engineering components is the important factors, which at times subordinate nature of the subsequent segments. It is vital in this way that the review of the tally at all phases of generation parts [4].

Most important requirements in the machining process are the surface roughness. The assessment of surface roughness is a result of the tool wear. At the point, when the wear of tool increment, likewise increments. The assurance of adequate cutting parameters is a significant process by means of obtained both least surface roughness values and long tool life. Different investigations have been made on the surface roughness in the machining process utilizing distinctive materials, cutting instruments, and trial and improvement strategies [5].

Surface finish of machined parts is absolutely critical in deciding their quality. This is not just a question for aesthetic purposes. In a few modern applications the machined parts must be in contact with different parts, surface completion is additionally a deciding component in characterizing the limit of wear, oil, and protection from fatigue [6].

Literature survey revealed a number of researchers; fabricate a separate regression model to build up a maximum comprehension of the impacts of spindle speed, cutting feed rate and depth of cut on the surface roughness [7]. The outcomes demonstrated the cutting feed as the most prevailing element and collaboration cutting feed-depth of cut, and cutting feed-spindle speed the most noteworthy.

An impact of machining parameters involves spindle speed, depth of cut and feed rate, on the quality of a generated surface in CNC end milling [4]. Three diverse workpiece materials were investigated to show the influence of variety workpiece material. The models of roughness as well as the importance of the machining parameters have been agreed upon ANOVA. The ANOVA organized that all the three cutting parameters (spindle speed, depth of cut and feed rate) also interactions of parameters take significant effect on roughness parameters considered in the present examination however the impacts differ with the idea of the material workpiece.

The controllable factors selected for his experimental work are cutting speed, feed rate, depth of cut, coolant and tool diameter of CNC end milling machine [8]. Mild steel was used as the workpiece and solid carbide cutter were used as an end mill cutter. Taguchi method and 
ANOVA have been used for analyzing the results. $\mathrm{L}_{18}$ orthogonal array has been prepared for experiments. The factual data can be applied in the industry to acquire the desirable Surface Roughness and Material Removal Rate for the work piece by using an adequate parameter association.

The machining variables that are influence on the surface roughness of end milling for hardened die steel H-13 [9]. Manner of Taguchi has been employed for the computation. The conclusions display that the higher level of cutting speed and minimized the feed rate will be decreased the surface roughness.

\section{THEORETICAL CONSIDERATIONS}

The designing and manufacturing of all complexes something's deal with the mathematical performance of curves and surfaces. The complication and precision of the designed parts concern upon the curve and the surface sort who's create the designed part. The mathematical impersonation of an engineering curve or surface of most concerns upon the equation grade of the curve, the grade of this curve, numbering of control points utilized to define the curve. Conclusion accuracy of the mathematical equation reduces when the degree of this equation increment [10].

In the present research Bezier surface was used. It can be express using the binomial representation of a Bezier curve. Each point on the Bezier surface can be situated at given value of the parametric pair by:

$P(u, w)=\sum_{i=0}^{n} \sum_{j=0}^{m} P_{i j} B_{i, n}(u) B_{j, m}(w)$

$B_{i, n}(u)$ and $B_{j, m}(w)$ are the Bernstein basis(blending) functions, defined in the same way as for Bezier curves $[11,12]$. The general matrix equation for a Bezier patch is:

$P(u, w)=U_{1, n} M_{B, n, n} P_{n, m} M_{B, m, m}^{T} W_{m, 1}^{T} \ldots \ldots$

The levels of cutting parameters are listed in table (1):
Where the size of the matrices are dependent on the dimensions of the control point array. Using the binomial representation of the cubic Bezier curve is used for the matrix equation for a patch defined by a $(4 \times 4)$ array of control points is [10].

$P(u, w)=U_{1 x 4} \cdot M_{B, 4 x 4} \cdot P_{4 x 4} \cdot M_{4 x 4}^{T} \cdot W_{4 x 1} \ldots \ldots$

Expanded equation (3) becomes:

$P(u, w)=\left[(1-u)^{3} 3 u(1-u)^{2} 3 u^{2}(1-u) u^{3}\right] . P \cdot\left[\begin{array}{c}(1-w)^{3} \\ 3 w(1-w)^{2} \\ 3 w^{2}(1-w) \\ w^{3}\end{array}\right] \ldots$

Where: $P=\left[\begin{array}{llll}P_{11} & P_{12} & P_{13} & P_{14} \\ P_{21} & P_{22} & P_{23} & P_{24} \\ P_{31} & P_{32} & P_{33} & P_{34} \\ P_{41} & P_{42} & P_{43} & P_{44}\end{array}\right] \ldots$

The matrix $[\mathrm{P}]$ : characteristic polygon of the points that be defined.

\section{EXPERIMENTAL WORK}

\subsection{Design of Experiment}

Taguchi analysis technique is a statistical mensuration of rendering applied in the existent work into predict an orthogonal-array and signal-to-noise analysis [13] Taguchi method-based design of experiment and $\mathrm{L}_{12}\left(4^{2}\right)$ is utilized for the parametric design surface according to MINITAB16 software as follow:

\section{STAT $\Rightarrow$ DOE $\Rightarrow$ Taguchi $\Rightarrow$ Create Taguchi Design}

Table (1): control factors and their levels

\begin{tabular}{|cc|ccc|}
\hline No. & Control factors & Level-1 & Level-2 & units \\
\hline $\mathbf{1}$ & Tool diameter & 6 & 8 & $(\mathrm{~mm})$ \\
\hline $\mathbf{2}$ & Feed rate & 200 & 500 & $(\mathrm{~mm} / \mathrm{min})$ \\
\hline $\mathbf{3}$ & Spindle speed & 1000 & 2500 & $($ r.p.m) \\
\hline $\mathbf{4}$ & Depth of cut & 0.2 & 0.5 & (mm) \\
\hline
\end{tabular}

The final layout of the experiments that is get from the MINITAB software is shown below in table (2) in term of number of levels. 
Table (2): The final layout of experiments according to L12.

\begin{tabular}{ccccc}
\hline No. & $\begin{array}{c}\text { Tool diameter } \\
(\mathbf{m m})\end{array}$ & $\begin{array}{c}\text { Feed rate } \\
(\mathbf{m m} / \mathbf{m i n})\end{array}$ & $\begin{array}{c}\text { Spindle speed } \\
(\mathbf{r . p . m})\end{array}$ & $\begin{array}{c}\text { Depth of cut } \\
(\mathbf{m m})\end{array}$ \\
\hline $\mathbf{1}$ & 6 & 200 & 1000 & 0.2 \\
$\mathbf{2}$ & 6 & 200 & 2500 & 0.2 \\
$\mathbf{3}$ & 6 & 200 & 2500 & 0.5 \\
$\mathbf{4}$ & 6 & 500 & 1000 & 0.5 \\
$\mathbf{5}$ & 6 & 500 & 2500 & 0.2 \\
$\mathbf{6}$ & 6 & 500 & 2500 & 0.5 \\
$\mathbf{7}$ & 8 & 200 & 2500 & 0.5 \\
$\mathbf{8}$ & 8 & 200 & 2500 & 0.2 \\
$\mathbf{9}$ & 8 & 200 & 1000 & 0.5 \\
$\mathbf{1 0}$ & 8 & 500 & 2500 & 0.2 \\
$\mathbf{1 1}$ & 8 & 500 & 1000 & 0.5 \\
$\mathbf{1 2}$ & 8 & 500 & 1000 & 0.2 \\
\hline
\end{tabular}

\subsection{Surface Design and Data Transfer}

The designed surface has been generated based on Bezier surface by using MATLAB and then transferred to

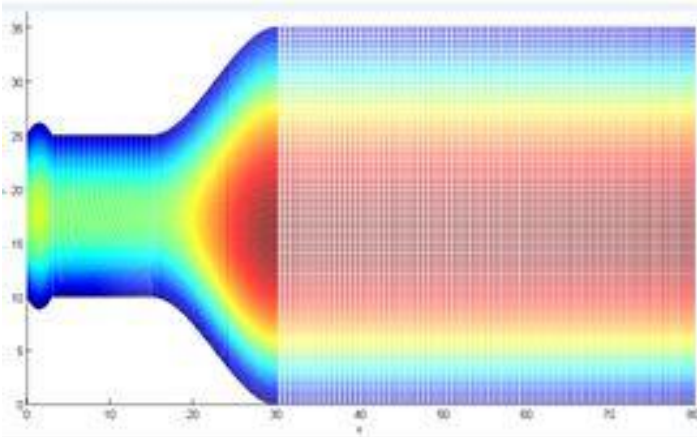

(a) the UGS-NX8-through (. dat) file to view the required shape. After the construction of the Bezier surface converted to a series of points as shown in figure $(1 \mathrm{a}, \mathrm{b})$.

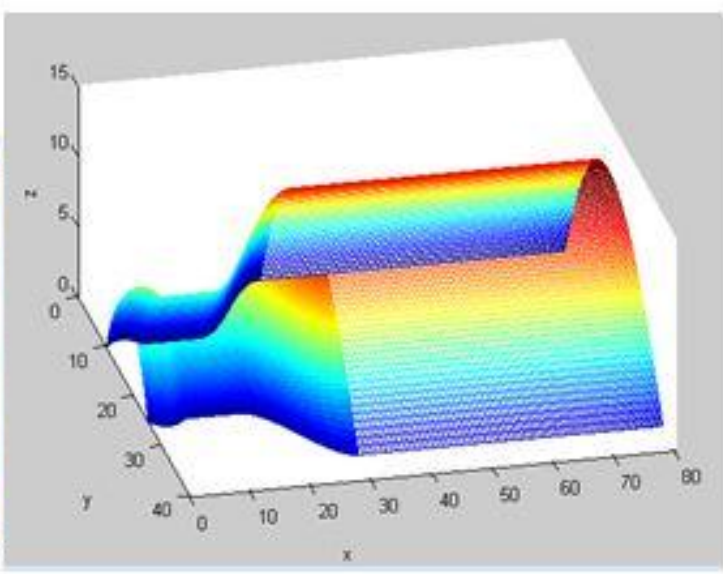

(b)

Fig. (1 a, b): Bezier surface of the proposed case study.

The data for each curve has been represented and saved in a single matrix of $(n \times 3)$. Each matrix is saved as (. dat) file and exported to the UG-NX program as shown in figure (2).

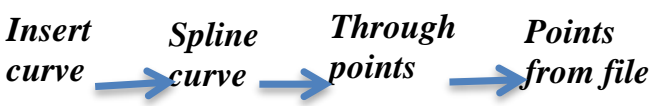

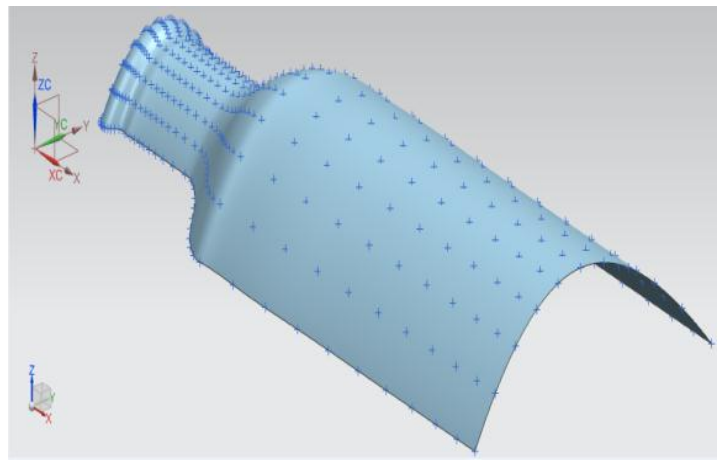

Fig. (2): Converting the points to a surface 


\subsection{CNC Milling Machine}

Figure (3) shows the CNC milling machine model XK7124, which was used in the machining process of the samples (12 samples) which machined in the present work

\subsection{Cutting Tools and Material}

Four types of cutting tool are used in this research shown in figure (4):
1. Flat-end mill tool and ball-end mill tool with diameter (Ø $6 \mathrm{~mm})$, that made from high-speed steel (HSS) whose applied for rough and finishing machining.

2. Flat-end mill tool and ball-end mill tool with diameter (Ø 8mm), that made from high-speed steel (HSS) whose applied for rough and finishing machining.

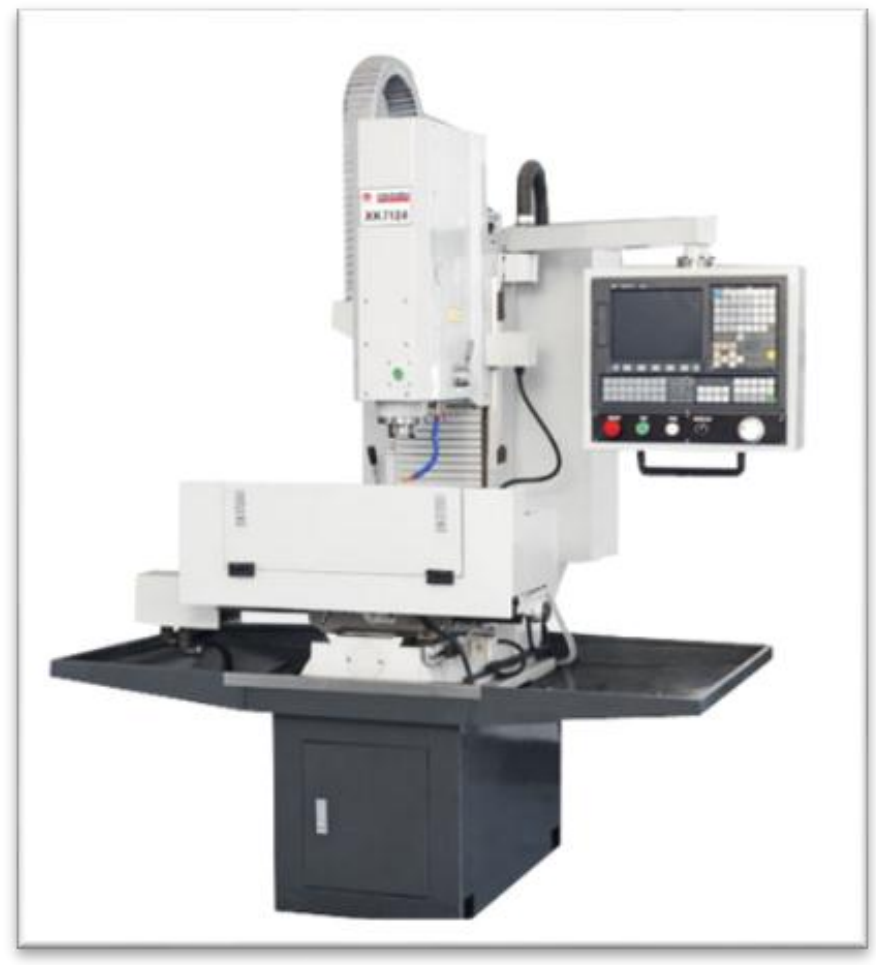

Fig. (3): XK7124 CNC milling machine

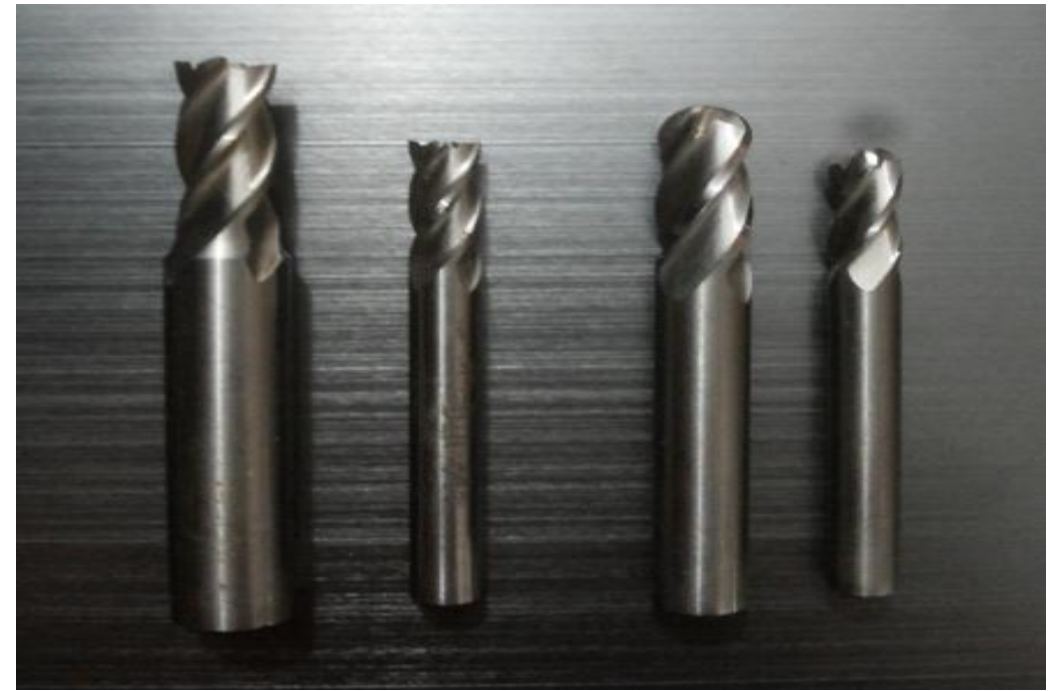


Fig. (4): Cutting tools.

\subsection{Tester of Surface Roughness}

An economical priced specified by a pocket-sized device that is portable surface roughness gage Mahr
Federal's patented is the appliance that one used to mensuration the surface roughness in this current work. Figure (5) shown the Pocket Surf gage that used in this study.

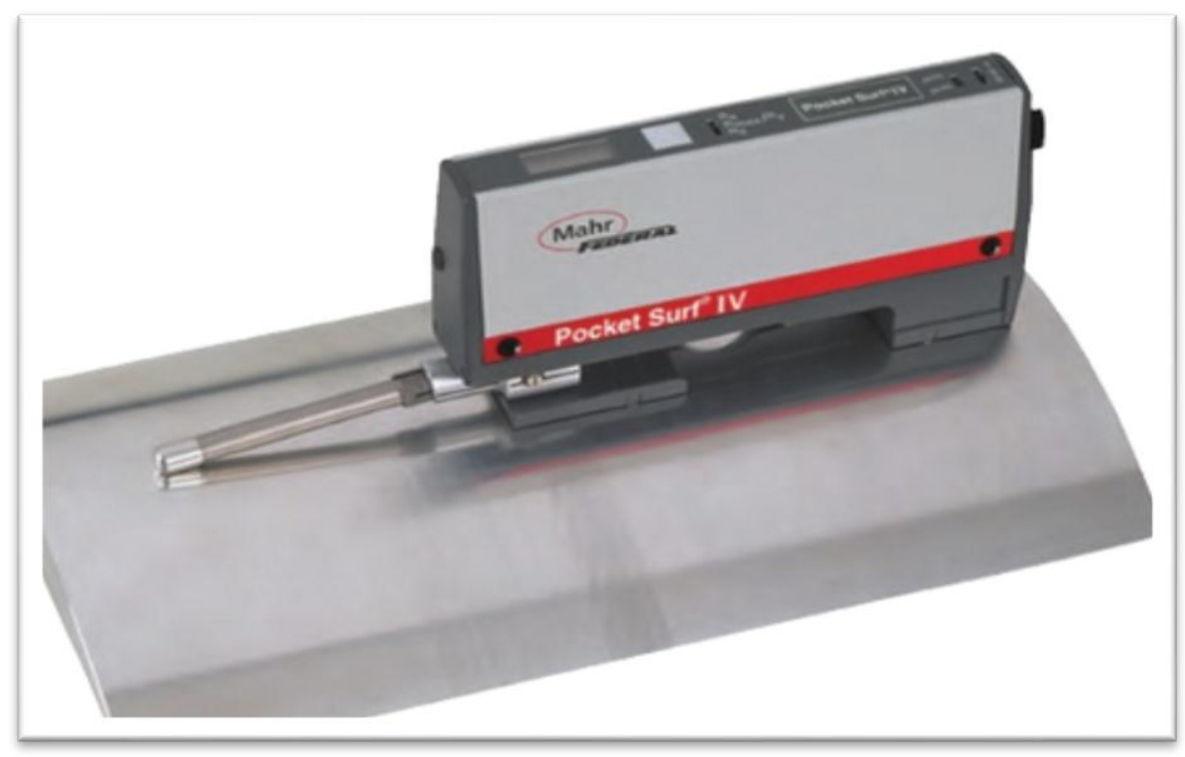

Fig. (5): Pocket Surf tester.

\subsection{Material of the Model}

The material of the model of all the experiments was carried out on aluminum alloy-7024. This model has been prepared as a block with a dimension of $(80 \mathrm{~mm} \times 40$ $\mathrm{mm} \times 40 \mathrm{~mm}$ ). The chemical compositions of the sheet material are analyzed by "spectrometer elements analysis" and the chemical compositions listed in Table (3).

Table (3): Chemical composition of the Aluminum alloy 7024 (\% of Mass)

\begin{tabular}{ccccccccccccc}
\hline $\begin{array}{c}\text { Element } \\
\begin{array}{c}\text { Stander } \\
\text { values [14] }\end{array}\end{array}$ & $\mathbf{S i}$ & $\mathbf{F e}$ & $\mathbf{C u}$ & $\mathbf{M n}$ & $\mathbf{M g}$ & $\mathbf{C r}$ & $\mathbf{N i}$ & $\mathbf{Z n}$ & $\mathbf{T i}$ & $\mathbf{V}$ & $\mathbf{P b}$ & $\mathbf{A l}$ \\
\hline $\begin{array}{c}\text { Actual } \\
\text { values. }\end{array}$ & 0.163 & 0.422 & 0.10 & $\begin{array}{c}0.10- \\
0.6\end{array}$ & $\begin{array}{c}0.50- \\
1.0\end{array}$ & $\begin{array}{c}0.05- \\
0.35\end{array}$ & - & $\begin{array}{c}3.0- \\
5.0\end{array}$ & 0.10 & - & - & remain \\
\hline
\end{tabular}

\subsection{Roughing and Finishing Process}

The milling process is done in two stages roughing and finishing. Material is separated as quickly as possible in roughing. The cutter of the milling machine removes material in layers while the surface is accomplished. At the roughing, elevation metal removal rates to minimize the machining time. The roughing is generally done in parallel layers until a specific profundity. The last surface quality isn't essential as a layer of material is left to finish. Figure (6) shows roughing process and finishing process for the machined part 

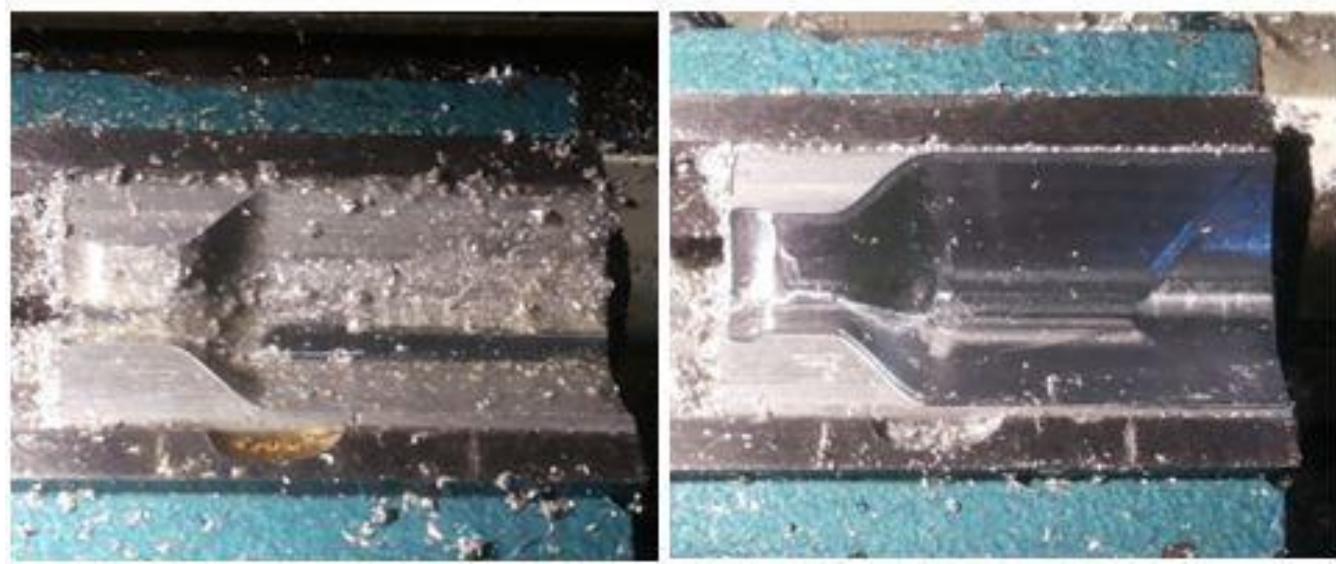

Fig. (6): Roughing and finishing process for the machined part.

\section{RESULTS}

Table (4) represents the experimental results of machining $\mathrm{Al}$ alloy-7024 as indicated by Taguchi $\mathrm{L}_{12}\left(2^{4}\right)$ orthogonal array. Different reaction attributes, to be specific, $\mathrm{Ra}$ in $\mu \mathrm{m}$ have been estimated. The normal (mean) of these qualities and signal to noise $(\mathrm{S} / \mathrm{N})$ ratio (in decibels) are appeared for every characteristic in the tables (5) and (6). Also figures (7) and (8) show the effect plot of the factors vs means and $\mathrm{S} / \mathrm{N}$ ratio.

\subsection{Optimum design conditions for surface Roughness (Ra)}

Figures (7) and (8) show the graph of effects Plot of machining factors vs. the response (Surface Roughness) for mean and $\mathrm{S} / \mathrm{N}$ ratio and table (4) which shows the results of means. As shown in this table, all the selected four parameters of tool diameter, spindle speed, feed rate and depth of cut significantly affect both the mean and the variation in the $(\mathrm{Ra})$ values.

The S/N ratio plot of surface roughness means that the optimization for this response is smaller is better. So, it is clear that the optimal parametric combinations for minimum $\mathrm{Ra}$ are tool diameter of $8 \mathrm{~mm}$, feed rate of 200 $\mathrm{mm} / \mathrm{min}$, spindle speed 2500 r.p.m and depth of cut 0.5 $\mathrm{mm}$. It is proposed that the parametric blend inside the considered range as specified above gives most minimal surface roughness $\mathrm{Ra}$ for finishing of Aluminum alloy7024.

Table (4): $\mathrm{L}_{12}$ Taguchi design and results

\begin{tabular}{|c|c|c|c|c|c|c|c|c|}
\hline No. & $\begin{array}{c}\text { Tool } \\
\text { diameter } \\
(\mathbf{m m})\end{array}$ & $\begin{array}{l}\text { Feed rate } \\
(\mathrm{mm} / \mathrm{min})\end{array}$ & $\begin{array}{c}\text { Spindle } \\
\text { speed } \\
\text { (r.p.m) }\end{array}$ & $\begin{array}{l}\text { Depth } \\
\text { of cut } \\
\text { (mm) }\end{array}$ & $\begin{array}{c}\text { Ra1 } \\
(\mu \mathrm{m})\end{array}$ & $\begin{array}{r}\text { Ra2 } \\
(\mu \mathrm{m})\end{array}$ & SNRA1 & MEAN1 \\
\hline 1 & 6 & 200 & 1000 & 0.2 & 1.44 & 2.21 & -5.41436 & 1.825 \\
\hline 2 & 6 & 200 & 2500 & 0.2 & 1.61 & 1.19 & -3.01919 & 1.4 \\
\hline 3 & 6 & 200 & 2500 & 0.5 & 1.51 & 0.51 & -1.03838 & 1.01 \\
\hline 4 & 6 & 500 & 1000 & 0.5 & 1.28 & 2.23 & -5.19257 & 1.755 \\
\hline 5 & 6 & 500 & 2500 & 0.2 & 2.37 & 1.68 & -6.25276 & 2.025 \\
\hline 6 & 6 & 500 & 2500 & 0.5 & 2.14 & 1.31 & -4.98014 & 1.725 \\
\hline 7 & 8 & 200 & 2500 & 0.5 & 1.2 & 1.32 & -2.01725 & 1.26 \\
\hline 8 & 8 & 200 & 2500 & 0.2 & 0.87 & 0.49 & 3.023348 & 0.68 \\
\hline 9 & 8 & 200 & 1000 & 0.5 & 0.57 & 0.43 & 5.936302 & 0.5 \\
\hline 10 & 8 & 500 & 2500 & 0.2 & 1.22 & 0.75 & -0.10914 & 0.985 \\
\hline 11 & 8 & 500 & 1000 & 0.5 & 1.41 & 1.07 & -1.9493 & 1.24 \\
\hline 12 & 8 & 500 & 1000 & 0.2 & 1.59 & 1.29 & -3.21412 & 1.44 \\
\hline
\end{tabular}


Table (5): The Response Table of "Means".

\begin{tabular}{|c|c|c|c|c|}
\hline Level & Tool diameter & Feed Rate & Spindle Speed & Depth of cut \\
\hline 1 & 1.623 & 1.112 & 1.352 & 1.393 \\
\hline 2 & 1.018 & 1.528 & 1.298 & 1.248 \\
\hline Delta & 0.606 & 0.416 & 0.054 & 0.144 \\
\hline Ranke & 1 & 2 & 4 & 3 \\
\hline
\end{tabular}

Table (6): The Response Table of "Signal to Noise" Ratios.

\begin{tabular}{|c|c|c|c|c|}
\hline Level & Tool diameter & Feed Rate & Spindle Speed & Depth of cut \\
\hline 1 & -4.3162 & -0.4216 & -1.9668 & -2.4977 \\
\hline 2 & 0.2783 & -3.6163 & -2.0562 & -1.5402 \\
\hline Delta & 4.5945 & 3.1948 & 0.0894 & 0.9575 \\
\hline Ranke & 1 & 2 & 4 & 3 \\
\hline
\end{tabular}

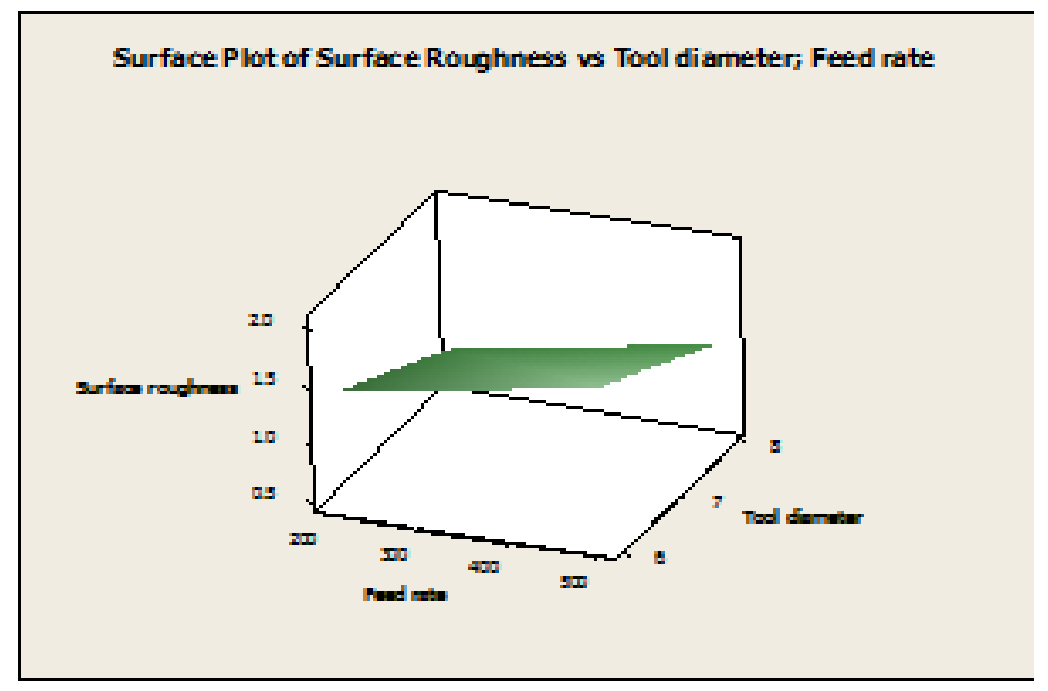

Fig. (7): main effect plot for means of surface roughness

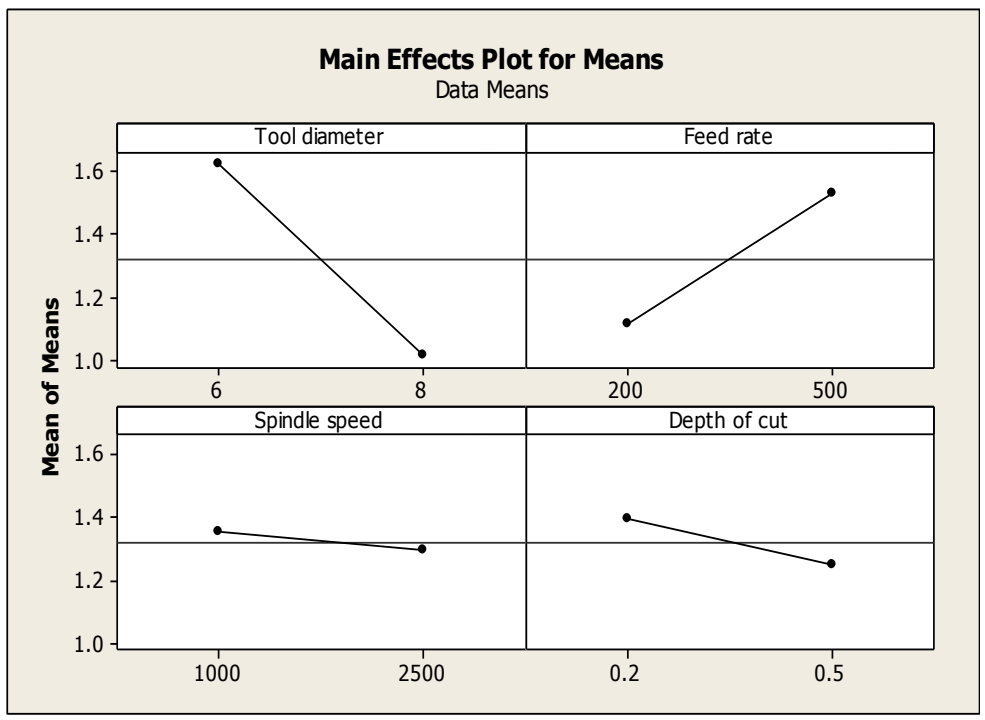

Fig. (8): main effects plot for signal to noise ratios of roughness. 


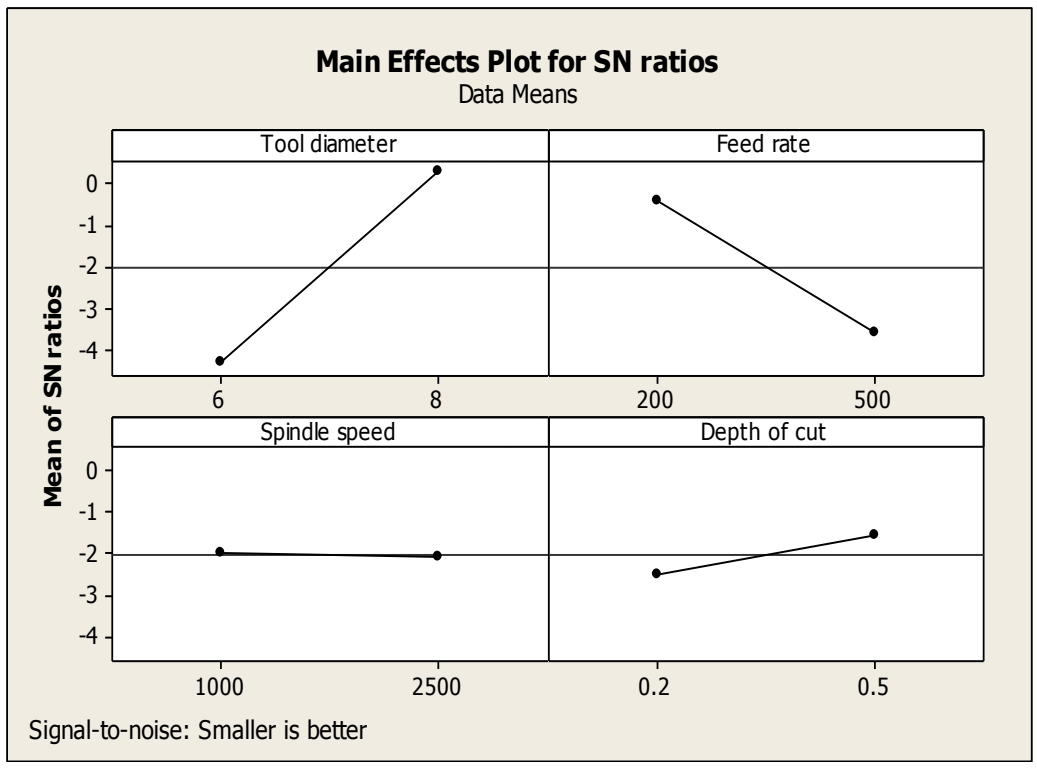

Fig. (9): The effect of "surface roughness" vs "tool diameter" \& "feed rate"..

\subsection{Surface plot of surface roughness vs design conditions}

From figures (9), (10) and (11), it was observed that most effected factors of surface roughness the tool diameter according to response table for means (4) and the increased of this factor will reduced the surface roughness. The relationships between feed rate and $\mathrm{Ra}$ proportional so, reduced feed will be decreased this response. At increased the spindle speed the surface roughness minimized.

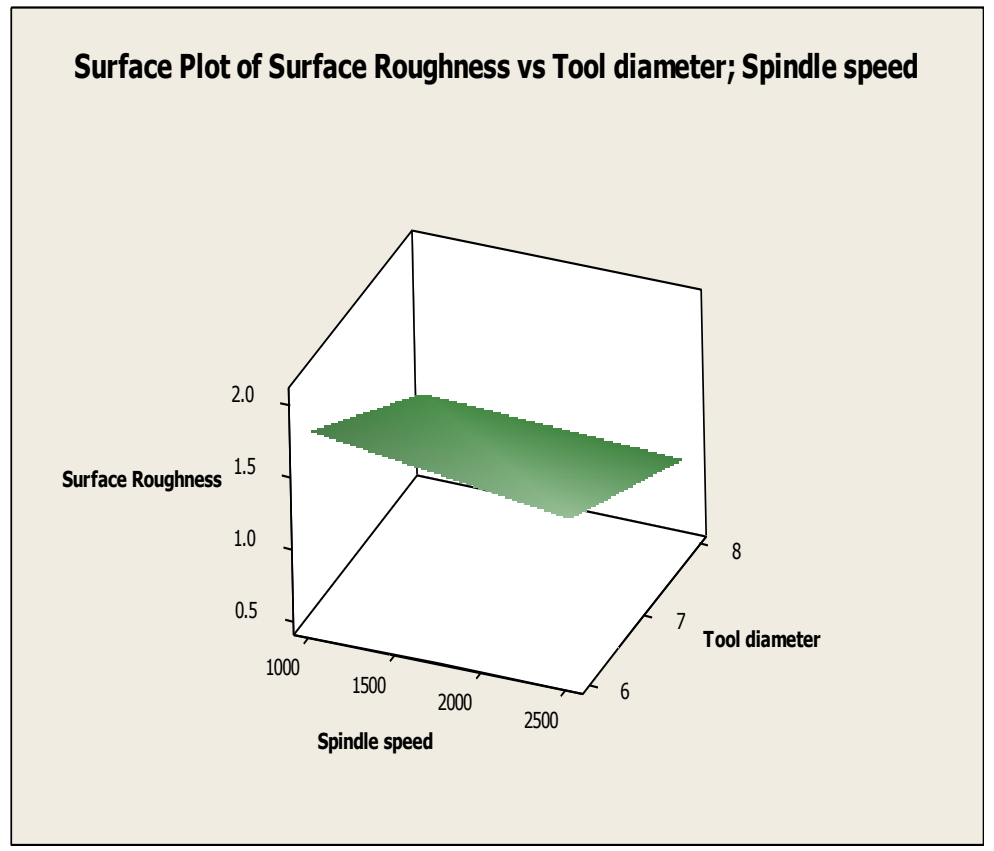

Fig. (10): The effect of "surface roughness" vs "tool diameter" \& "spindle speed" 


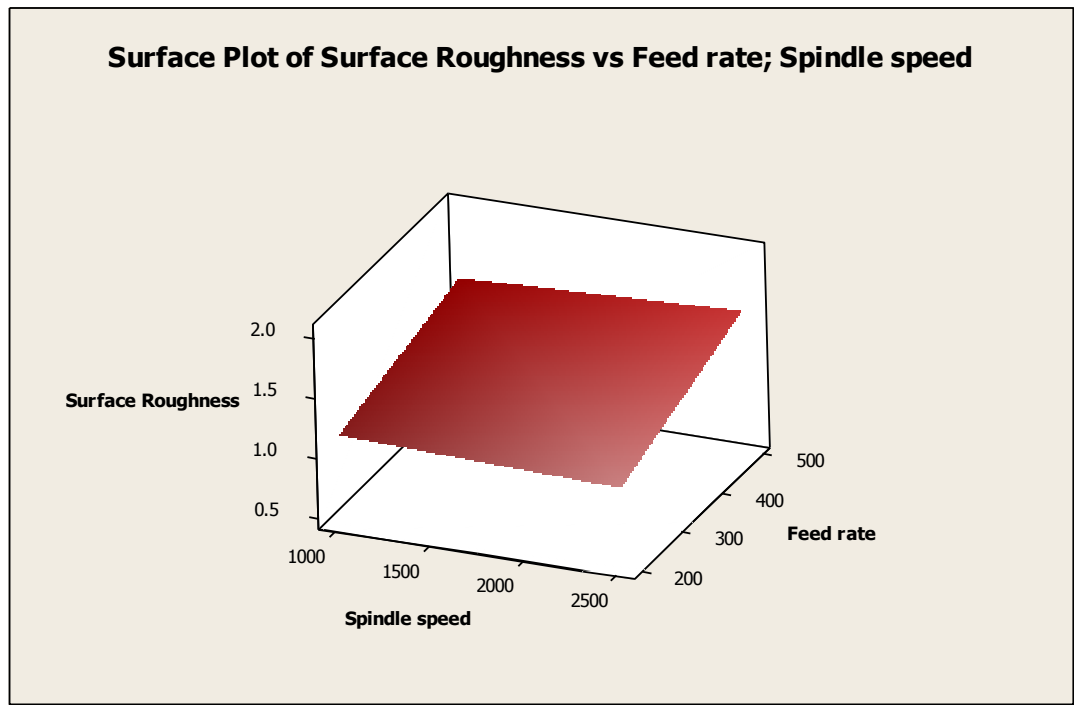

Fig. (11): The effect of "surface roughness" vs "feed rate" \& "spindle speed"

\section{CONCLUSIONS}

A combination of examinations has been led with a specific end goal to start to describe the variables influencing surface roughness for the roughing and finishing process. Taguchi technique was good tool for predicting the process outputs, from experiments:

- Tool diameter has the highest effected factors (rank one) followed by feed rate (rank two) then depth of cut which is the third effected factors and finally spindle speed with the less effected factors of surface roughness (rank four).

- The optimal parametric combinations for minimum $\mathrm{Ra}$ are tool diameter of $(8 \mathrm{~mm})$, feed rate of $(200$ $\mathrm{mm} / \mathrm{min}$ ), spindle speed (2500 r.p.m) and cut depth (0.5 mm).

- The relationships between feed rate and Ra proportional so, reduced feed rate will be decreased this response.

- The increased of tool diameter will reduced the surface roughness.

- At increased the spindle speed the surface roughness will be minimized.

\section{Acknowledgment:}

This work was supported by University of Technology, Department of Production Engineering and Metallurgy, which is gratefully acknowledged.

\section{References}

[1] Young Keun Choi, tool path generation and 3D tolerance analysis for free-form surfaces, Ph. D thesis, Texas A\&M University, 2004.

[2] QIANG JI AND MICHAEL M. MAREFAT, Machine interpretation of CAD data for manufacturing applications , University of Arizona, Tucson, ACM Computing Surveys, Vol. 24, No. 3, September 1997.

[3] Julie Z. Zhang, Joseph C. Chen and E. Daniel Kirby, Surface roughness optimization in an end-milling operation using the Taguchi design method, Journal of Materials Processing Technology 184 (2007) 233239.

[4] B. C. Routara, A. Bandyopadhyay \& P. Sahoo, Roughness modeling and optimization in $\mathrm{CNC}$ end milling using response surface method: effect of workpiece material variation, Int J Adv Manuf Technol (2009) 40:1166-1180.

[5] Babur Ozcelik and Mahmut Bayramoglu, The statistical modeling of surface roughness in highspeed flat end milling, International Journal of Machine Tools \& Manufacture 46 (2006) 13951402.

[6] M.R. SOLEYMANI YAZDI and A. KHORRAM, Modeling and Optimization of Milling Process by using RSM and ANN Methods, IACSIT International Journal of Engineering and Technology, Vol.2, No.5, October 2010 ISSN: 1793-8236.

[7] Mohammed T. Hayajneh, Montasser S. Tahat and Joachim Bluhm, A Study of the Effects of Machining Parameters on the Surface Roughness in the EndMilling Process, Jordan Journal of Mechanical and Industrial Engineering, Volume 1, Number 1, Sep. (2007) $1-5$.

[8] Piyush pandey, Prabhat kumar sinha, Vijay kumar and Manas tiwari, Process Parametric Optimization of CNC Vertical Milling Machine Using Taguchi Technique in Varying Condition, IOSR Journal of 
Mechanical and Civil Engineering (IOSR-JMCE), Volume 6, Issue 5 (May. - Jun. 2013), 34-42.

[9] Jatin, Pankaj Sharma, Effect of machining parameters on output characteristics of CNC milling using Taguchi optimization technique, International Journal of Engineering, Business and Enterprise Applications, (2013) 64-67 .

[10]David Salomon, CURVES AND SURFACES FOR COMPUTER GRAPHICS, Springer Science and Business Media, Inc2006.

[11] Andrés Iglesias, Bezier Curves and Surfaces, University of Cantabria, Santander, Spain, 2001.

[12] Wisam K. Hamdan, Jamal H. Mohamed and Nareen Hafudh Obaeed, Influence of some relevant process parameters on the surface roughness of surfaces produced by ISMF process, Engineering and Technology Journal,Vol. 32, Part (A), No.8, (2014) 1942-1957.

[13] M. J. Kadhim, K. A. Sukkar, A. S. Abbas and N. H. Obaeed, Investigation Nano coating for Corrosion Protection of Petroleum Pipeline Steel Type A106 Grade B; Theoretical and Practical Study in Iraqi Petroleum Sector, Engineering and Technology Journal Vol. 35, Part A, No. 10, (2017) 1042-1051.

[14] The Aluminum association International, Alloy Designations and Chemical Composition Limits for Wrought Aluminum and Wrought Aluminum Alloys, Wilson Boulevard, Arlington, VA 222, www.aluminum.org, 2015. 